\title{
Research on the contribution rate of scientific and technological progress to Chongqing's economic growth Based on the Solow Growth model
}

\author{
Yixin Zheng ${ }^{1, \mathrm{a}}$, Yucheng Wang 2 ,b \\ ${ }^{1}$ Westa College, Southwest university, Chongqing, China \\ ${ }^{2}$ School of Automotive engineering, Chongqing university, Chongqing, China
}

\begin{abstract}
In the context of current proposed transformation of economic development of the region are actively rely on capital from investment to promote economic growth mode to a mode relying on technological progress to promote economic growth up. Therefore, this paper selects the sample data of Chongqing from 2010 to 2017, and based on the empirical analysis of the Solow residual value model, using SPSS statistics 25 software, studies the contribution of Chongqing's capital investment and labor input, especially technological progress, to economic growth. The research shows that the contribution rate of Chongqing's capital input to economic growth has always been at a relatively high level, but it has shown a general downward trend. At the same time, the elasticity coefficient of capital input is small, indicating that its contribution to economic growth is small; the contribution rate of labor input fluctuates greatly but the impact is small; the contribution rate of scientific and technological progress to economic growth shows an overall upward trend, which has become an important factor for driving Chongqing's economic growth after capital investment. Therefore, governments must accelerate the transformation of the economic development mode, vigorously promote the development of science and technology, and rely more on scientific and technological progress to promote economic growth and achieve sustainable economic development.
\end{abstract}

\section{Introduction}

As the second largest economy in the world, China's economic growth rate has been stable at about $7 \%$ per year. However, China's economic growth relies too much on the input of human capital and physical capital, which has led to the slowdown of China's economic growth in recent years. Therefore, China is currently committed to transforming its economic development mode, mainly relying on innovation and technological progress to promote economic growth. The Outline of the National Medium and Long-Term Science and Technology Development Plan (2006-2020) proposes that "by 2020, the contribution rate of scientific and technological progress will reach more than $60 \%$." Research on the contribution rate of scientific and technological progress to economic growth has become a hot issue in the field of economics in China. Especially in the case of responding to new crown epidemic, how to ensure steady economic growth, fundamentally necessary to the economic growth mode from the support rely on physical capital investment to support scientific and technological progress to improve the economic growth quality and efficiency up. This makes the research on the relationship between technological progress and economic growth more important and urgent.

\section{Literature Review}

Since the early 20th century, the continuous evolution of macroeconomic growth theory has promoted the development of scientific and technological progress contribution rate estimation methods. Cobb and Douglas derived the Cobb-Douglas production function that measures the technical relationship between factor input and output, which laid the theoretical foundation for estimating the contribution rate of scientific and technological progress. [1] Subsequently, Solow first proposed the Solow residual value based on the $C D$ production function to estimate the contribution rate of technological progress. [2] Denison classified input elements in more detail, and expanded the concept of technological progress in Solow's residual value with total factor productivity. [3] Therefore, " total factor productivity " is called " technical progress in a broad sense," or directly called " technical progress." The scientific and technological progress mentioned in this article is "broad scientific and technological progress" and is the endogenous driving force for economic growth.

In the study of domestic scholars, most of them use Cobb-Douglas production function and Solow model to study the contribution rate of China's scientific and technological progress to economic growth. From a macro 
perspective, Zhou Shaosen and Hu Delong proposed that scientific and technological progress is mainly reflected by five major factors such as human capital, research and development, unit energy economic efficiency, industrial structure adjustment, and marketization degree. The extended Solow residual value model is used. Empirical analysis of the contribution of various factors to economic growth from 1980 to 2007 in China, and found that the overall contribution rate of scientific and technological progress in the country was low at that time, and economic growth mainly relied on physical capital accumulation. [4] LI Lanlan, the military and various gram MENT to expand the use of the Cobb-Douglas production function and Solow residual value model estimates the contribution rate of science and technology for national economic growth, the results showed that: China's regional imbalance level of technological development, Shanghai The highest contribution rate of scientific and technological progress is $54.19 \%$; Beijing is followed by $48.90 \%$; Sichuan is the lowest at 28.59\% . [5] Zheng Shilin, Zhang Meichen processed R\&D capital stock and re-estimated China 19902017 National and provincial-level scientific and technological progress contribution rate, the results show : 1990 - 2017 years, the average annual contribution of scientific and technological progress of the national economic growth rate of 48.97 percent, China's economic growth has become the most important source of inspiration. [6] Jiao Shuaitao, Sun Qiubi based on panel data of 30 provinces and cities in China from 2008 to 2017 , using a variety of spatial measurement models to empirically analyze the spatial spillover effect of technological innovation on economic growth. The results show that technological innovation has a positive effect on economic growth, and the space spillover effect caused by technological innovation is also positive. [7] From a local perspective, Li Shiwen and $\mathrm{Hu}$ Kai selected various indicators of total agricultural output, capital input, labor input, and land area input in Jiangxi Province from 1978 to 2017 as input and output indicators, using the Solow residual value method The contribution rate of agricultural scientific and technological progress in Jiangxi Province is calculated, and the results show that: the contribution rate of scientific and technological progress to economic growth in Jiangxi Province is 59\%, which is an important factor to promote economic growth. [8] Song Jie uses comparative analysis, stationarity test, cointegration test Granger causality test, factor analysis method and IRFThe analysis method studies the relationship between technological innovation and economic growth in Shandong Province, and analyzes the article from the perspective of technological innovation input and output. Finally, it is concluded that technological innovation input and output have a long-term equilibrium relationship with economic growth, and the two can directly promote Economic Growth. [9] Ji Weidong and Ge Yihong used the Solow residual value model to study the contribution of Hohhot' s scientific and technological progress to economic growth, and found that the contribution rate of scientific and technological progress in Hohhot fluctuated significantly, but showed an overall upward trend. [10]

In summary, the current research on the contribution rate of scientific and technological progress to economic growth is relatively mature, so this article will also use the commonly used Solow residual value model, focusing on the micro perspective, taking Chongqing as an example, selecting data from 2010-2017 to study The contribution rate of Chongqing's scientific and technological progress to economic growth, and an inductive analysis of the results and policy recommendations.

\section{Model selection}

In this paper, the Solow residual value model is used to calculate the contribution rate of technological progress. According to the Solow growth model:

$$
Y=A F(K, L)=A K^{\alpha} L^{\beta}
$$

Among them, $\alpha$ and $\beta$ are the elasticity of capital and labor output. When the return to scale is constant, that is, $\alpha+\beta=1, \alpha$ and $\beta$ are the proportions of capital and labor distribution in total output, respectively. Take the logarithm of the production function of formula (1) and derive the time $\mathrm{t}$ :

$$
\frac{1}{A} \cdot \frac{\Delta A}{\Delta t}=\frac{1}{Y} \cdot \frac{\Delta Y}{\Delta t}-\alpha \times \frac{1}{K} \cdot \frac{\Delta K}{K}-\beta \times \frac{1}{L} \cdot \frac{\Delta L}{\Delta t}
$$

Among them, another $\triangle \mathrm{t}=1$, and the "Solow residual value" can be further obtained:

$$
\frac{\Delta A}{A}=\frac{\Delta Y}{Y}-\alpha \times \frac{\Delta K}{K}-\beta \times \frac{\Delta L}{L}
$$

In formula (3), the molecular formulas represent the growth rate of scientific and technological progress, economic growth rate, capital investment growth rate, and labor force investment growth rate, respectively. The formula for calculating the scientific and technological contribution rate is:

$$
\text { Technology contribution rate }=\frac{\frac{\Delta A}{\Delta}}{\frac{\Delta \mathrm{Y}}{\mathrm{Y}}} \times 100 \%
$$

Next, we will further determine the values of $\alpha$ and $\beta$. The most commonly used methods for determining the values of $\alpha$ and $\beta$ include empirical estimation, regression, and formula derivation. Comparatively speaking, the empirical method is subjective and lacks sufficient theoretical basis, while the regression method is to calculate the elasticity coefficient of each input and output through the statistical data of the past years, which is more objective and can effectively avoid artificial estimation. The resulting judgment error.

Therefore, after taking the logarithm of (1) in this paper, we get:

$$
\operatorname{Ln} Y=\operatorname{Ln} A+\alpha \operatorname{Ln} K+\beta \operatorname{LnL}
$$

Since the marginal returns to scale remain unchanged, $\alpha+\beta=1$. Based on the statistical data from 2010 to 2017, multiple linear regression analysis can be performed to obtain the estimated values of $\alpha$ and $\beta$. 


\section{Data analysis}

\subsection{Selection of Data}

This article selects the annual statistical data of Chongqing from 2010 to 2017 , in which the economic output index is measured by the local gross national income, the capital input is measured by the local fixed capital input value, and the labor input is measured by the number of local employees. The above data are all from the official website of the National Bureau of Statistics, and the data are shown in Table 1.

Table1. Sample data and elastic coefficient estimates

\begin{tabular}{cccccc}
\hline Years & $\begin{array}{c}\text { Technological } \\
\text { progress growth } \\
\text { rate } \\
(\%)\end{array}$ & $\begin{array}{c}\text { GDP } \\
\text { growth } \\
\text { rate } \\
(\%)\end{array}$ & $\begin{array}{c}\text { Contribution rate of } \\
\text { scientific and } \\
\text { technological progress } \\
(\%)\end{array}$ & $\begin{array}{c}\text { Capital } \\
\text { investment } \\
\text { contribution rate } \\
(\%)\end{array}$ & $\begin{array}{c}\text { Labor input } \\
\text { contribution } \\
\text { rate } \\
(\%)\end{array}$ \\
\hline 2010 & $9.38 \%$ & $21.37 \%$ & $43.89 \%$ & $132.34 \%$ & $33.32 \%$ \\
2011 & $9.69 \%$ & $26.31 \%$ & $36.83 \%$ & $44.58 \%$ & $100.91 \%$ \\
2012 & $5.94 \%$ & $13.60 \%$ & $43.67 \%$ & $124.26 \%$ & $34.85 \%$ \\
2013 & $-5.32 \%$ & $10.93 \%$ & $-48.67 \%$ & $177.95 \%$ & $126.53 \%$ \\
2014 & $5.31 \%$ & $10.90 \%$ & $48.71 \%$ & $162.66 \%$ & $28.44 \%$ \\
2015 & $10.40 \%$ & $11.00 \%$ & $94.55 \%$ & $153 \%$ & $2.45 \%$ \\
2016 & $12.23 \%$ & $10.70 \%$ & $114.30 \%$ & $110.37 \%$ & $-6.17 \%$ \\
2017 & $13.52 \%$ & $9.49 \%$ & $142.47 \%$ & $96.31 \%$ & $-16.54 \%$ \\
\hline
\end{tabular}

\subsection{Estimation of the elastic coefficient}

This paper takes the data of Chongqing from 2010 to 2017 and uses SPSS Statistics 25 software to carry out multiple linear regression analysis of equation (5), and obtains the capital elasticity coefficient $\alpha$ and labor elasticity coefficient $\beta$, the values are shown in Table 1 .

\subsection{Calculation of contribution rate of each element}

The above analyzes the output elasticity of capital $\alpha$ and the output elasticity of labor $\beta$, and the growth rate of scientific and technological progress $(\triangle \mathrm{A} / \mathrm{A})$ can be calculated according to equation (3). According to the formula (4), the contribution rate of science and technology progress, capital investment contribution rate and labor input contribution rate of Chongqing from 2010 to 2017 can be further obtained. The values are shown in Table 2. The fluctuation of the contribution rate of each factor is shown in Figure 1.

Table2. Chongqing's contribution rate of various factors

\begin{tabular}{cccccc}
\hline Years & $\begin{array}{c}\text { Technological } \\
\text { progress growth } \\
\text { rate } \\
(\%)\end{array}$ & $\begin{array}{c}\text { GDP } \\
\text { growth } \\
\text { rate } \\
(\%)\end{array}$ & $\begin{array}{c}\text { Contribution rate of } \\
\text { scientific and } \\
\text { technological progress } \\
(\%)\end{array}$ & $\begin{array}{c}\text { Capital } \\
\text { investment } \\
\text { contribution rate } \\
(\%)\end{array}$ & $\begin{array}{c}\text { Labor input } \\
\text { contribution } \\
\text { rate } \\
(\%)\end{array}$ \\
\hline 2010 & $9.38 \%$ & $21.37 \%$ & $43.89 \%$ & $132.34 \%$ & $33.32 \%$ \\
2011 & $9.69 \%$ & $26.31 \%$ & $36.83 \%$ & $44.58 \%$ & $100.91 \%$ \\
2012 & $5.94 \%$ & $13.60 \%$ & $43.67 \%$ & $124.26 \%$ & $34.85 \%$ \\
2013 & $-5.32 \%$ & $10.93 \%$ & $-48.67 \%$ & $177.95 \%$ & $126.53 \%$ \\
2014 & $5.31 \%$ & $10.90 \%$ & $48.71 \%$ & $162.66 \%$ & $28.44 \%$ \\
2015 & $10.40 \%$ & $11.00 \%$ & $94.55 \%$ & $153 \%$ & $2.45 \%$ \\
2016 & $12.23 \%$ & $10.70 \%$ & $114.30 \%$ & $110.37 \%$ & $-6.17 \%$ \\
2017 & $13.52 \%$ & $9.49 \%$ & $142.47 \%$ & $96.31 \%$ & $-16.54 \%$ \\
\hline
\end{tabular}

The contribution rate of each factor $(\%)$

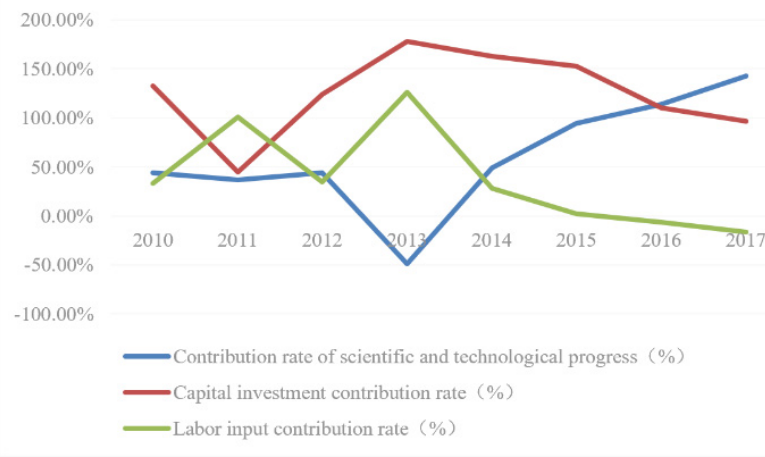

Fig1. Chongqing's contribution rate trends of each factor (2010-2017)

\section{Results and discussion}

\subsection{Results}

From 2010 to 2017, Chongqing's contribution rate of scientific and technological progress fluctuated greatly. Especially in 2013, the contribution rate of scientific and technological progress was $-48.67 \%$. The contribution rate of scientific and technological progress to economic growth in other years was positive. On the whole, except for 2013, the contribution rate of Chongqing's scientific and technological progress has shown an overall upward trend in the selected time period. The contribution of scientific and technological progress to economic growth in 2016 and 2017 even exceeded 100\%, respectively, $114.3 \%$ And $142.27 \%$.

At the same time, the capital investment contribution rate and labor input contribution rate fluctuated very much, but in recent years have shown a downward trend, especially in 2016 and 2017, Chongqing labor input contribution rate are negative, respectively $-6.17 \%$ and $16.54 \%$; The contribution rate of capital investment to economic growth has always been at a high level, with an average contribution rate of around $100 \%$.

\subsection{Discussion}

According to the research results, except for 2013, Chongqing's scientific and technological progress contributed more than $35 \%$ to economic growth in the selected time period, especially after 2016, the contribution rate exceeded $100 \%$, indicating scientific and technological progress It is an important factor driving Chongqing's economic growth.

In the comparison of the contribution of capital input and labor input to economic growth, this article finds the following: First, compared with capital growth rate and labor growth rate, the growth rate of scientific and technological progress shows an overall upward trend, while at the same time, capital growth rate The labor growth rate and labor growth rate showed an overall downward trend, indicating that technological progress to promote economic growth is slowly replacing the previous trend of relying on capital and labor input to drive economic growth. Second, Chongqing's capital 
investment has a higher contribution rate to economic growth, indicating that regional economic growth is still mainly achieved by a large amount of capital investment and capital accumulation. At the same time, the labor contribution rate to economic growth is low, indicating that the labor force is not The decisive factor driving economic growth. Third, although Chongqing mainly relied on capital input to promote economic growth in the early stage, the elasticity of capital input $(\alpha)$ is small and the elasticity of labor input $(\beta)$ is large, indicating that expansion solely relying on capital input has low economic benefits for economic growth It may also bring damage to the ecological environment and pollution costs, which is not conducive to the sustainable development of the economy.

In terms of regional GDP, this study finds that in the selected time period, Chongqing's regional GDP has shown an upward trend year by year, but the regional GDP growth rate has shown an overall downward trend, indicating that the transformation of economic development mode There are still problems in the process, and the region as a whole is not yet adapted to the transition from capital and human input to economic growth to technological progress to economic growth.

\section{Conclusion}

According to the questions and results of this article, the following suggestions are made:

First, in view of the current situation of relying mainly on capital investment to drive economic growth, it is still necessary to increase physical capital investment, but it must grasp the direction of investment to make it conducive to the optimization of industrial structure and the development of high-tech industries. At the same time, we must increase investment in scientific and technological capital, attract foreign investment and advanced technology, and permanently drive technological progress.

Second, we must fully understand the role of scientific and technological progress in economic growth, we can increase the investment of scientific research funds in universities and other scientific research institutions, help small and medium-sized enterprises to carry out technological innovation, strengthen cooperation between scientific research institutions and enterprises, and promote the transformation of scientific and technological achievements. Realize economic benefits. As a result, the contribution rate of other factors of production increased. Fundamentally speaking, to completely get out of the crisis, we must transform the economic growth model, from the growth model relying on investment support to the growth model relying on scientific and technological progress, improving quality and efficiency.

Third, change the mode of economic development should not be quick and quick, and provide good policy support and infrastructure guarantee for technological innovation. In view of the current situation that the region cannot adapt to relying on technological progress to drive economic growth, the government should actively guide the development of high-tech industries, introduce advanced technologies and high-tech talents, learn advanced experience, improve supporting infrastructure construction, and provide good local science and technology development. surroundings.

\section{References}

1. Cobb, CW and Douglas, PH "A Theory of Production." The American Economic Review, 1928, 18 is (. 1), pp.139 - 165 .

2. Solow, RM "Technical Change and the Aggregate Production Function. "Review of Economics and Statistics, 1957.

3. Schumpeter forward., "The Theory of Economic Development," Kongwei Yan translated. Beijing: Beijing Publishing House, 2008.

4. Zhou Shaosen, $\mathrm{Hu}$ Delong, "Research on the contribution rate of scientific and technological progress to economic growth," China Soft Science, pp. 35-39, February 2010

5. Li Lanlan, Zhu Kejun, and Guo Haixiang, "An empirical study on the calculation of the contribution rate of scientific and technological progress in various provinces and cities in China," China Population-Resources and Environment, pp.55-61, April 2011.

6. Zheng Shilin, Zhang Meichen, "scientific and technological progress contribution rate of China's economic growth estimate: 1990 - 2017 Nian," World Economy, pp. 74-97, October 2019.

7. Jiao Shuaitao, Sun Qiubi, "An empirical analysis of the spillover effect of technological innovation and consumption upgrade on economic growth," Statistics and Information Forum, pp. 74-81, April 2020.

8. Li Shiwen, Hu Kai, "Calculation and Forecast of the Contribution Rate of Agricultural Science and Technology Progress in Jiangxi Province," Regional Economy, pp. 159-163, 2019.

9. Song Jie, "Empirical Research on Technology Innovation and Economic Growth in Shandong Province," Shandong University, 2019.

10. Ji Weidong, Ge Yihong, "Research on the calculation and evaluation of the contribution rate of scientific and technological progress in Hohhot," Inner Mongolia Science Technology and Economy, pp.2023, March 2020. 